\title{
Genome Defense and DNA Methylation in Neurospora
}

\author{
E.U. SELKER \\ Department of Biology and Institute of Molecular Biology, University of Oregon, Eugene, Oregon 97403
}

The continuity of life is attributed to the faithful copying of DNA. It is therefore intriguing that some organisms chemically modify their DNA in ways that can lead to heritable changes. Soon after the discovery that a fraction of cytosines are methylated in DNA of some eukaryotes - including vertebrates, plants, and some fungi- evidence began to accumulate that DNA methylation is inherently mutagenic. For example, in mammals, where methylation is almost exclusively found at cytosines immediately preceding guanines ("CpG" dinucleotides), it was noticed that methylated chromosomal regions are typically unexpectedly poor in CpGs and unexpectedly rich in TpGs and CpAs, apparently as a result of $\mathrm{C}$ to $\mathrm{T}$ mutations at sites subject to methylation (Bird 1980). It was assumed that this reflected the fact that 5-methyl-cytosine, like cytosine, is somewhat unstable, spontaneously decomposing to 5-methyl-uridine (thymine) and that G:T mismatches are repaired less efficiently than G:U mismatches. Discovery of repeat-induced point mutation (RIP) in the filamentous fungus Neurospora crassa raised the possibility that DNA methyltransferases and similar enzymes may be directly responsible for such mutations (Selker 1990b; Freitag et al. 2002). What positive functions does DNA methylation serve? Although the control and function of DNA methylation are both still hotly debated, it is becoming increasingly clear that DNA methylation is one of several mechanisms that defends the eukaryotic genomes from mischievous DNA. Neurospora provided an early, and exceptionally clear, illustration of this and it continues to provide a convenient model to elucidate DNA methylation and other epigenetic processes.

\section{THE METHYLATION LANDSCAPE}

Although Neurospora was initially reported to have no methylated DNA (Antequera et al. 1984), observations in the 1980s revealed cytosine methylation in this model eukaryote. After methods became established to transform Neurospora, it was noticed that some transforming sequences are subject to de novo methylation, especially when they are repeated (Bull and Wootton 1984; Selker et al. 1987a; Orbach et al. 1988). At the same time, natural patches of methylation were found associated with several 5S rRNA pseudogenes (Selker and Stevens 1985; Margolin et al. 1998). No methylation has been reported in any of the hundreds of protein-coding genes that have been studied. Indeed, as discussed below, recent analyses suggest that most DNA methylation is associated with relics of transposons. We now know that $\sim 1.5 \%$ of the cytosines in the DNA of $N$. crassa are methylated (Russell et al. 1987; Foss et al. 1993).

The first methylated region characterized in detail is the 1.6-kb zeta-eta $(\zeta-\eta)$ region (Selker and Stevens 1985; Selker et al. 1993b). This consists of a diverged tandem duplication of a $0.8-\mathrm{kb}$ segment of DNA, including a $5 \mathrm{~S}$ rRNA gene. Comparison of this region with the corresponding chromosomal region of strains lacking the duplication led to the idea that repeated sequences can somehow induce DNA methylation (Selker et al. 1985, 1987a; Grayburn and Selker 1989) and ultimately led to the discovery of the genome defense system that we named RIP (Selker et al. 1987b; Selker and Garrett 1988; Cambareri et al. 1989). Both the $\zeta-\eta$ region and the psi63 ( $\psi 63)$ region, the second methylated region discovered in Neurospora (Metzenberg et al. 1985; Foss et al. 1993; Miao et al. 1994; Margolin et al. 1998), are products of RIP.

\section{THE PROTOTYPICAL GENOME DEFENSE SYSTEM: RIP}

RIP detects duplicated sequences in the haploid genomes of special dikaryotic cells resulting from fertilization and then riddles both copies of the duplicated sequence with polarized transition mutations; $\mathrm{C}: \mathrm{G}$ pairs are replaced with T:A pairs (Cambareri et al. 1989). RIP has a clear sequence preference (Cs preceding As are mutated most frequently), making it straightforward to recognize sequences that have been mutated by RIP (Margolin et al. 1998). In a single passage through the sexual cycle, up to $\sim 30 \%$ of the G:C pairs in duplicated sequences can be changed to A:T pairs (Cambareri et al. 1991). After RIP, remaining cytosines are generally methylated, including those not in symmetrical sequences (e.g., CpGs) (Selker et al. 1993a). The methylation does not depend on the continued presence of sequence duplications and is normally stable through numerous rounds of DNA replication (Selker and Garrett 1988; Singer et al. 1995). DNA molecules show different patterns and levels of modification (Selker and Stevens 1985; Selker et al. 1993a). This heterogeneous methylation can extend beyond the mu- 
tated region and even beyond the edge of the segment that was originally duplicated (Cambareri et al. 1989; Selker et al. 1993a; Irelan and Selker 1997; Miao et al. 2000).

Results of genome-wide analyses of DNA methylation suggest that the vast majority of methylated residues are in relics of RIP (Galagan et al. 2003; Selker et al. 2003). Indeed, the only methylation not known to have resulted from RIP is that in the tandemly arranged rDNA (Perkins et al. 1986). A survey of methylated Neurospora sequences isolated by affinity chromatography using the methyl-binding domain (MBD) of MeCP2 revealed clear evidence of RIP in 47 of 51 sequenced fragments (Selker et al. 2003). Analysis of these sequences revealed significant similarities with a variety of transposable elements identified in other organisms, including both retrotransposons (e.g., lolligag, Tad, Tcen, and DAB1) and DNAtype transposons (e.g., Dodo1, Dodo2, Dodo3, listless, dPunt, Punt3, and Nogo) (Selker et al. 2003). Similar information came from large-scale genome sequencing projects. About $10 \%$ of the genome is composed of repetitive DNA and most of this is identifiable as transposonlike sequences that have been riddled with mutations by RIP (Galagan et al. 2003). Not a single intact transposable element was identifiable, consistent with failures to detect transpositions in standard Neurospora strains (Kinsey and Helber 1989). We conclude that RIP is an efficient genome defense mechanism. Does this mean that Neurospora cannot generate gene families by gene duplications? Nearly $20 \%$ of $N$. crassa genes are found in multigene families, but, interestingly, nearly all of the paralogs are sufficiently divergent and/or short that they should be invisible to RIP (Galagan et al. 2003). Thus, although Neurospora has gene families, RIP is presumably an obstacle to evolution of new genes through gene duplication (Galagan and Selker 2004).

\section{DE NOVO AND MAINTENANCE METHYLATION IN NEUROSPORA}

Laboratory experiments revealed that most products of RIP, but not their unmutated counterparts, are methylated (Selker et al. 1987a, 1993a; Cambareri et al. 1991; Singer et al. 1995; Miao et al. 2000). Similarly, predicted products of RIP identified in the genome based on their sequence composition are generally methylated (Galagan et al. 2003; Selker et al. 2003). In principle, such methylation could reflect signals for de novo methylation that work in vegetative cells. Alternatively, the mutated sequences may be methylated because of propagation of methylation established earlier (e.g., during RIP) and they could lack the capacity to trigger methylation de novo in vegetative cells. These possibilities were tested by determining whether a given sequence can induce methylation after it is stripped of its methylation by molecular cloning or by drug treatment (Singer et al. 1995). Such experiments revealed that, in general, sequences altered by RIP can trigger de novo methylation in vegetative cells. Most sequences mutated by RIP become remethylated both at their original genomic location and at arbitrary chromosomal positions (Selker et al. 1987a). Some products of RIP with relatively few mutations, however, do not normally become remethylated at their original site, suggesting that the observed methylation represents propagation of methylation established earlier (Singer et al. 1995). Although surprising, considering that this methylation is heterogeneous and is not limited to symmetrical sites, the capacity of Neurospora to perform such "maintenance methylation" on some sequences was experimentally demonstrated (Selker et al. 2002).

\section{cis-ACTING SIGNALS THAT CONTROL DNA METHYLATION}

As mentioned above, some transforming sequences are subject to de novo methylation without going through the sexual cycle (Bull and Wootton 1984; Selker et al. 1987a, 1993a; Orbach et al. 1988; Selker 1990a; Pandit and Russo 1992; Romano and Macino 1992). We have found that sequences differ in their susceptibility to methylation in vegetative cells. Native, unmutated sequences are not susceptible, while many foreign sequences with resemblance to sequences mutated by RIP are (M. Freitag and E. Selker, unpubl.). This methylation appears loosely correlated with the copy number of transforming DNA. A1though single-copy sequences are less frequently methylated than multicopy sequences (Pandit and Russo 1992; Romano and Macino 1992; Selker et al. 1993b), multicopy sequences are not always methylated (Selker and Garrett 1988).

Observations on the specificity of methylation in $\mathrm{Neu}$ rospora led to the "collapsed chromatin model," in which DNA methylation is the fate of sequences that are inert (i.e., completely inactive [Selker 1990a]). One prediction of the model was that short sequences should not have the ability to trigger methylation, for example, when inserted into an active gene. To explore this and other possibilities, we developed efficient gene-targeting systems that allowed us to test the methylation potential of single copies of sequences integrated precisely and without extraneous sequences at a common chromosomal position (at the am locus on LG VR [Miao et al. 1994] or the his3 locus on LG IR; Margolin et al. 1997). Using these systems, we demonstrated that mutations per se (e.g., numerous $\mathrm{A}: \mathrm{T}$ to $\mathrm{G}: \mathrm{C}$ mutations) do not trigger methylation and that products of RIP, such as the $\zeta-\eta$ region, effectively contain multiple, additive methylation signals, whose effects can spread hundreds of base pairs into flanking sequences. Fragments of the $\zeta-\eta$ region as short as 171 bp can trigger methylation (Selker et al. 1993b; Miao et al. 2000). We found that mutation density per se does not determine whether sequences become methylated and that neither A:T-richness nor high densities of TpA dinucleotides, typical attributes of methylated sequences in Neurospora, are essential features of methylation signals. Nevertheless, both A:T-richness and high densities of TpA dinucleotides appear to promote methylation in Neurospora. These and other findings from "transplanting" small fragments of genes, pieces of DNA mutated by RIP, and synthetic sequences led us to con- 
clude that methylated sequences do not simply reflect the absence of signals that prevent methylation; they apparently contain positive signals that trigger methylation (Miao et al. 2000).

To better define the nature of these signals, we developed a more sensitive assay to test the capacity of short (25-100-bp) synthetic oligonucleotides to trigger methylation at a specific locus (Tamaru and Selker 2003). Our system used a his-3 targeting vector carrying a 100-bp $\zeta-\eta$ segment surrounded by a lightly RIP-mutated allele of the am gene. We demonstrated that this mosaic construct does not trigger methylation itself at his-3, but does provide a sensitive context to assess the potential of various sequences to induce methylation. A variety of random sequences consisting of only $\mathrm{A}$ and $\mathrm{T}$ residues triggered methylation of nearby cytosines. Introduction of $\mathrm{G}: \mathrm{C}$ pairs into the A:T-rich sequences was strongly inhibitory and both As and Ts were found to be required on the same strand to trigger significant methylation. Nevertheless, neither TpA nor ApT dinucleotides were essential. Tests of 20-, 25-, 40-, and 80-mer fragments of the most potent sequence, (TAAA)n, showed that longer tracts of this sequence act as stronger signals. It seems possible that an unidentified "A:T-hook"-type protein mediates methylation in Neurospora. Consistent with this possibility, we found that Distamycin A, an analog of the A:T-hook motif, interferes with de novo methylation in Neurospora (Tamaru and Selker 2003). Nevertheless, some of our findings do not support this hypothesis. In particular, we found that sequences with only two bp A:T tracts (e.g., (CTA)n) can induce methylation. In addition, using A:T-hook protein HMG-I (kindly provided by R. Reeves, Washington State University, Pullman), we showed that the sequence preference for HMG-I binding does not simply correlate with the sequence preferences for de novo methylation. Additional work will be required to determine how relics of RIP, and similar degenerate sequences, are recognized to trigger methylation in vegetative cells of Neurospora.

\section{FORWARD GENETICS APPROACH TO ELUCIDATE CONTROL AND FUNCTION OF DNA METHYLATION}

Neurospora is well suited to identify components of the methylation machinery by genetic approaches that do not rest on prior knowledge or preconceptions. We have successfully used several approaches to identify mutants defective in methylation ( $\mathrm{dim}$ ), but have not yet saturated the Neurospora genome for such mutations. DNA methylation can silence genes in Neurospora (Rountree and Selker 1997), allowing for the direct selection of mutations that affect DNA methylation. Nevertheless, most known dim mutants have been identified in other ways, such as in "brute force" screens using Southern hybridization to identify mutants that affect methylation (Foss et al. 1993, 1995). Two mutants, dim-2 and dim-5, abolish all detectable DNA methylation. Mapping and complementation studies revealed that the dim-2 gene encodes a DNA methyltransferase (DMTase) (Kouzminova and Selker 2001), while dim-5 encodes a histone methyltransferase (HMTase) (Tamaru and Selker 2001).

Biochemical characterization of DIM-2 should be interesting. This predicted 1454-amino-acid protein is responsible for all detected DNA methylation in $\mathrm{Neu}$ rospora, including methylation in a variety of sequence contexts. Mutations preventing all methylation have not been described in other eukaryotes, which may reflect the fact that DNA methylation results from multiple DMTases in most organisms that have been characterized and that DNA methylation is essential in some organisms. Although the DIM-2 carboxy-terminal domain includes all the well conserved motifs characteristic of DMTases, its amino-terminal domain shows no marked similarity to previously described proteins (Kouzminova and Selker 2001).

\section{CONTROL OF DNA METHYLATION BY HISTONE METHYLATION}

The discovery that dim-5 encodes a HMTase provided the first indication that DNA methylation is regulated by histone methylation, at least in some organisms. Biochemical work showed that DIM-5 is specific for lysine 9 of histone $\mathrm{H} 3$ and that it efficiently trimethylates this residue in vitro and in vivo, unlike all previously characterized HMTases (Tamaru and Selker 2001; Tamaru et al. 2003). In order to determine whether histone $\mathrm{H} 3$ is the critical substrate for DIM-5 in vivo, we transformed a Dim $^{+}$Neurospora strain with engineered histone H3 genes carrying a mutation at lysine 9 that would preclude methylation. Amino acid substitutions at lysine 9 dramatically reduced DNA methylation, implicating histone $\mathrm{H} 3$ as the critical substrate for DNA methylation (Tamaru and Selker 2001). Evidence that some DNA methylation in Arabidopsis is also controlled by histone methylation came soon thereafter (Jackson et al. 2002; Malagnac et al. 2002). Interestingly, the critical mark in Arabidopsis appears to be di-, rather than tri-, methyl-lysine 9 (Jackson et al. 2004). Most recently, Jenuwein and colleagues have provided evidence in mice that trimethylation of lysine 9 of histone $\mathrm{H} 3$ directs DNA methylation to major satellite repeats at pericentric heterochromatin (Lehnertz et al. 2003). The extent to which DNA methylation is controlled by histones in eukaryotes is not yet known.

\section{SEARCH FOR OTHER COMPONENTS OF DNA METHYLATION PATHWAY}

In principle, forward genetics should reveal all components of the DNA methylation pathway except for those that are essential or redundant. However, use of reverse genetics and biochemical approaches can facilitate the identification of components in the methylation process. For example, evidence from other systems that a heterochromatin protein, HP1 (Eissenberg and Elgin 2000), binds methylated lysine 9 of histone H3 (Bannister et al. 2001; Jacobs et al. 2001; Lachner et al. 2001), led us to search for an HP1 homolog in Neurospora and to test its possible involvement in DNA methylation by disrupting 
the HP1 gene (hpo) by RIP. We found that HP1 is indeed essential for DNA methylation in Neurospora, implying that this protein directs DIM-2 to DNA associated with chromatin in which histone H3 is methylated at lysine 9 (Freitag et al. 2004a).

Clues that the RNAi machinery may be involved in DNA methylation (Wassenegger et al. 1994; Aufsatz et al. 2002; Chan et al. 2004) prompted us to test the components of the Neurospora RNAi machinery, including apparent RNA-dependent RNA polymerases, dicers, argonautes, and RecQ helicase homologs that had been identified by genetic or bioinformatics approaches (Galagan et al. 2003). We found no evidence that any of the RNAi machinery is involved in initiation or maintenance of DNA methylation (Freitag et al. 2004b). In contrast, mutational analyses of histone deacetylase genes of $\mathrm{Neu}$ rospora revealed that at least one of these genes is involved in DNA methylation in Neurospora (K. Smith et al., unpubl.), consistent with the observation that the histone deacetylase inhibitor Trichostatin A reduces DNA methylation in some chromosomal regions of this organism (Selker 1998).

\section{CONCLUSIONS}

Why control DNA methylation through histone methylation? In the last few years it has become increasingly clear that histones are more than structural proteins; they are informational molecules (Jenuwein and Allis 2001). Particular combinations of posttranslational modifications of histones, including phosphorylation, methylation, acetylation, ubiquitination, and ADP ribosylation, can influence the function of the associated DNA and the modifications can depend on the presence or absence of other modifications. For example, methylation of lysine 9 on histone $\mathrm{H} 3$ is inhibited by phosphorylation of serine 10 and methylation of lysine 4, which are associated with active sequences (Rea et al. 2000; E. Berge et al., unpubl.) and there are indications that histone acetylation also influences methylation of lysine 9 (Selker 1998; Nakayama et al. 2001; K. Smith et al., unpubl.). Thus histones are well suited to integrate information bearing on the DNA that they are associated with.

Neurospora provided the first example of a genome defense system, RIP, and has more recently revealed two additional genetic mechanisms related to RNA interference (RNAi) mechanisms discovered in plants and animals that should also resist change in the genome. The first, "quelling," is specific to the vegetative phase of the Neurospora life cycle and is responsible for destroying RNA homologous to aberrant RNAs, for example, resulting from expression of tandem arrays of transgenes (Romano and Macino 1992; Catalanotto et al. 2002). The second, meiotic silencing by unpaired DNA (MSUD) (Aramayo and Metzenberg 1996; Shiu et al. 2001), scans paired homologs in meiosis for unpaired sequences and then destroys RNA matching unpaired DNA (Shiu and Metzenberg 2002; Lee et al. 2004). DNA methylation is commonly associated with both sequences mutated by RIP and with transgenes that trigger quelling, but it is not required for either process (Cogoni et al. 1996; Kouzminova and Selker 2001). Similarly, the RNAi processes are not required for DNA methylation. Thus, DNA methylation may be considered a fourth genome defense system, although there are undoubtedly additional connections between Neurospora's genome defense systems that are yet to be elucidated.

It should be interesting to discover similarities and differences between the Neurospora genome defense systems and those in other organisms. For example, we need to better characterize how DNA methylation controls transposable elements in Neurospora and mammals. In mammals, DNA methylation appears to block initiation of transcription, but not transcription elongation (Jones 1999); while in Neurospora, DNA methylation does not appear to inhibit transcription initiation, but nonetheless prevents accumulation of transcripts (Rountree and Selker 1997). Results of in vivo labeling experiments in Neurospora and nuclear run-on assays suggest that methylation interferes with elongation, but it remains possible that methylation also triggers RNA degradation (e.g., by an RNAi pathway). Another difference between Neurospora and mammals pertains to how methylation is perceived. Whereas mammals possess a variety of protein complexes that specifically recognize methylated DNA and recruit chromatin modification factors (Bird and Wolffe 1999), Neurospora lacks MBD proteins, but preliminary investigations suggest that Neurospora uses different proteins to recognize methylated sequences $(\mathrm{G}$. Kothe et al., unpubl.). Finally, until we have a better understanding about how different organisms "decide" which sequences to methylate, the possible generality of mechanisms involved in the function and control of DNA methylation will not be clear.

\section{ACKNOWLEDGMENTS}

I thank Michael Freitag, Keyur Adhvaryu, and Kristina Smith for comments on the manuscript and thank present and past members of my laboratory for their contributions to our research. I gratefully acknowledge funding from NIH (grant GM35690) and NSF (grant MCB0131383), which contributed to this work.

\section{REFERENCES}

Antequera F., Tamame M., Villanueva J.R., and Santos T. 1984. DNA methylation in the fungi. J. Biol. Chem. 259: 8033.

Aramayo R. and Metzenberg R.L. 1996. Meiotic transvection in fungi. Cell 86: 103

Aufsatz W., Mette M.F., van der Winden J., Matzke A.J., and Matzke M. 2002. RNA-directed DNA methylation in Arabidopsis. Proc. Natl. Acad. Sci. (suppl. 4) 99: 16499.

Bannister A.J., Zegerman P., Partridge J.F., Miska E.A., Thomas J.O., Allshire R.C., and Kouzarides T. 2001. Selective recognition of methylated lysine 9 on histone H3 by the HP1 chromo domain. Nature 410: 120.

Bird A.P. 1980. DNA methylation and the frequency of CpG in animal DNA. Nucleic Acids Res. 8: 1499.

Bird A.P. and Wolffe A.P. 1999. Methylation-induced repression-Belts, braces, and chromatin. Cell 99: 451.

Bull J.H. and Wootton J.C. 1984. Heavily methylated amplified DNA in transformants of Neurospora crassa. Nature 310: 701 . 
Cambareri E.B., Singer M.J., and Selker E.U. 1991. Recurrence of repeat-induced point mutation (RIP) in Neurospora crassa. Genetics 127: 699.

Cambareri E.B., Jensen B.C., Schabtach E., and Selker E.U. 1989. Repeat-induced G-C to A-T mutations in Neurospora. Science 244: 1571.

Catalanotto C., Azzalin G., Macino G., and Cogoni C. 2002. Involvement of small RNAs and role of the qde genes in the gene silencing pathway in Neurospora. Genes Dev. 16: 790 .

Chan S.W., Zilberman D., Xie Z., Johansen L.K., Carrington J.C., and Jacobsen S.E. 2004. RNA silencing genes control de novo DNA methylation. Science 303: 1336.

Cogoni C., Irelan J.T., Schumacher M., Schmidhauser T.J., Selker E.U., and Macino G. 1996. Transgene silencing of the al-1 gene in vegetative cells of Neurospora is mediated by a cytoplasmic effector and does not depend on DNA-DNA interactions or DNA methylation. EMBO J. 15: 3153.

Eissenberg J.C. and Elgin S.C. 2000. The HP1 protein family: Getting a grip on chromatin. Curr. Opin. Genet. Dev. 10: 204.

Foss H.M., Roberts C.J., Claeys K.M., and Selker E.U. 1993. Abnormal chromosome behavior in Neurospora mutants defective in DNA methylation. Science 262: 1737.

. 1995. Abnormal chromosome behavior in Neurospora mutants defective in DNA methylation (correction). Science 267: 316 .

Freitag M., Williams R.L., Kothe G.O., and Selker E.U. 2002. A cytosine methyltransferase homologue is essential for repeatinduced point mutation in Neurospora crassa. Proc. Natl. Acad. Sci. 99: 8802

Freitag M., Hickey P.C., Khlafallah T.K., Read N.D., and Selker E.U. 2004a. HP1 is essential for DNA methylation in $\mathrm{Neu}$ rospora. Mol. Cell 13: 427.

Freitag M., Lee D.W., Kothe G.O., Pratt R.J., Aramayo R., and Selker E.U. 2004b. DNA methylation is independent of RNA interference in Neurospora. Science 304: 1939.

Galagan J.E. and Selker E.U. 2004. RIP: The evolutionary cost of genome defense. Trends Genet. 20: 417.

Galagan J.E., Calvo S.E., Borkovich K.A., Selker E.U., Read N.D., Jaffe D., FitzHugh W., Ma L.J., Smirnov S., Purcell S., Rehman B., Elkins T., Engels R., Wang S., Nielsen C.B., Butler J., Endrizzi M., Qui D., Ianakiev P., Bell-Pedersen D., Nelson M.A., Werner-Washburne M., Selitrennikoff C.P., Kinsey J.A., and Braun E.L., et al. 2003. The genome sequence of the filamentous fungus Neurospora crassa. Nature 422: 859.

Grayburn W.S. and Selker E.U. 1989. A natural case of RIP: Degeneration of DNA sequence in an ancestral tandem duplication. Mol. Cell. Biol. 9: 4416.

Irelan J.T. and Selker E.U. 1997. Cytosine methylation associated with repeat-induced point mutation causes epigenetic gene silencing in Neurospora crassa. Genetics 146: 509.

Jackson J.P., Lindroth A.M., Cao X., and Jacobsen S.E. 2002. Control of CpNpG DNA methylation by the KRYPTONITE histone H3 methyltransferase. Nature 416: 556.

Jackson J.P., Johnson L., Jasencakova Z., Zhang X., Perez-Burgos L., Singh P.B., Cheng X., Schubert I., Jenuwein T., and Jacobsen S.E. 2004. Dimethylation of histone H3 lysine 9 is a critical mark for DNA methylation and gene silencing in Arabidopsis thaliana. Chromosoma 112: 308.

Jacobs S.A., Taverna S.D., Zhang Y., Briggs S.D., Li J., Eissenberg J.C., Allis C.D., and Khorasanizadeh S. 2001. Specificity of the HP1 chromo domain for the methylated N-terminus of histone H3. EMBO J. 20: 5232.

Jenuwein T. and Allis C.D. 2001. Translating the histone code. Science 293: 1074.

Jones P.A. 1999. The DNA methylation paradox. Trends Genet. 15: 34 .

Kinsey J.A. and Helber J. 1989. Isolation of a transposable element from Neurospora crassa. Proc. Natl. Acad. Sci. 86: 1929.

Kouzminova E.A. and Selker E.U. 2001. Dim-2 encodes a DNAmethyltransferase responsible for all known cytosine methylation in Neurospora. EMBO J. 20: 4309.

Lachner M., O'Carroll D., Rea S., Mechtler K., and Jenuwein T. 2001. Methylation of histone H3 lysine 9 creates a binding site for HP1 proteins. Nature 410: 116.
Lee D.W., Seong K.Y., Pratt R.J., Baker K., and Aramayo R. 2004. Properties of unpaired DNA required for efficient silencing in Neurospora crassa. Genetics 167: 131.

Lehnertz B., Ueda Y., Derijck A.A., Braunschweig U., PerezBurgos L., Kubicek S., Chen T., Li E., Jenuwein T., and Peters A.H. 2003. Suv39h-mediated histone h3 lysine 9 methylation directs DNA methylation to major satellite repeats at pericentric heterochromatin. Curr. Biol. 13: 1192.

Malagnac F., Bartee L., and Bender J. 2002. An Arabidopsis SET domain protein required for maintenance but not establishment of DNA methylation. EMBO J. 21: 6842.

Margolin B.S., Freitag M., and Selker E.U. 1997. Improved plasmids for gene targeting at the his-3 locus of Neurospora crassa by electroporation. Fungal Genet. Newsl. 44: 34.

Margolin B.S., Garrett-Engele P.W., Stevens J.N., Yen-Fritz D., Garrett-Engele C., Metzenberg R.L., and Selker E.U. 1998. A methylated Neurospora 5S rRNA pseudogene contains a transposable element inactivated by RIP. Genetics 149: 1787.

Metzenberg R.L., Stevens J.N., Selker E.U., and MorzyckaWroblewska E. 1985. Identification and chromosomal distribution of 5S rRNA genes in Neurospora crassa. Proc. Natl. Acad. Sci. 82: 2067.

Miao V.P., Freitag M., and Selker E.U. 2000. Short TpA-rich segments of the zeta-eta region induce DNA methylation in Neurospora crassa. J. Mol. Biol. 300: 249.

Miao V.P.W., Singer M.J., Rountree M.R., and Selker E.U. 1994. A targeted replacement system for identification of signals for de novo methylation in Neurospora crassa. Mol. Cell. Biol. 14: 7059 .

Nakayama J., Rice J.C., Strahl B.D., Allis C.D., and Grewal S.I. 2001. Role of histone H3 lysine 9 methylation in epigenetic control of heterochromatin assembly. Science 292: 110.

Orbach M.J., Schneider W.P., and Yanofsky C. 1988. Cloning of methylated transforming DNA from Neurospora crassa in Escherichia coli. Mol. Cell. Biol. 8: 2211.

Pandit N.N. and Russo V.E.A. 1992. Reversible inactivation of a foreign gene, $h p h$, during the asexual cycle in Neurospora crassa transformants. Mol. Gen. Genet. 234: 412.

Perkins D.D., Metzenberg R.L., Raju N.B., Selker E.U., and Barry E.G. 1986. Reversal of a Neurospora translocation by crossing over involving displaced rDNA, and methylation of the rDNA segments that result from recombination. Genetics 114: 791.

Rea S., Eisenhaber F., O’Carroll D., Strahl B.D., Sun Z.W., Schmid M., Opravil S., Mechtler K., Ponting C.P., Allis C.D., and Jenuwein T. 2000. Regulation of chromatin structure by site-specific histone H3 methyltransferases. Nature 406: 593.

Romano N. and Macino G. 1992. Quelling: Transient inactivation of gene expression in Neurospora crassa by transformation with homologous sequences. Mol. Microbiol. 6: 3343.

Rountree M.R. and Selker E.U. 1997. DNA methylation inhibits elongation but not initiation of transcription in Neurospora crassa. Genes Dev. 11: 2383.

Russell P.J., Rodland K.D., Rachlin E.M., and McCloskey J.A. 1987. Differential DNA methylation during the vegetative life cycle of Neurospora crassa. J. Bacteriol. 169: 2902.

Selker E.U. 1990a. DNA methylation and chromatin structure: A view from below. Trends Biochem. Sci. 15: 103.

1990 b. Premeiotic instability of repeated sequences in Neurospora crassa. Annu. Rev. Genet. 24: 579.

1998. Trichostatin A causes selective loss of DNA methylation in Neurospora. Proc. Natl. Acad. Sci. 95: 9430.

Selker E.U. and Garrett P.W. 1988. DNA sequence duplications trigger gene inactivation in Neurospora crassa. Proc. Natl. Acad. Sci. 85: 6870.

Selker E.U. and Stevens J.N. 1985. DNA methylation at asymmetric sites is associated with numerous transition mutations. Proc. Natl. Acad. Sci. 82: 8114.

Selker E.U., Fritz D.Y., and Singer M.J. 1993a. Dense non-symmetrical DNA methylation resulting from repeat-induced point mutation (RIP) in Neurospora. Science 262: 1724.

Selker E.U., Jensen B.C., and Richardson G.A. 1987a. A portable signal causing faithful DNA methylation de novo in Neurospora crassa. Science 238: 48. 
Selker E.U., Stevens J.N., and Metzenberg R.L. 1985. Rapid evolutionary decay of a novel pair of 5S RNA genes. In Molecular genetics of filamentous fungi (ed. W. Timberlake), p. 309. Alan R. Liss, New York.

Selker E.U., Cambareri E.B., Jensen B.C., and Haack K.R. 1987b. Rearrangement of duplicated DNA in specialized cells of Neurospora. Cell 51: 741.

Selker E.U., Richardson G.A., Garrett-Engele P.W., Singer M.J., and Miao V. 1993b. Dissection of the signal for DNA methylation in the $\zeta-\eta$ region of Neurospora. Cold Spring Harbor Symp. Quant. Biol. 58: 323.

Selker E.U., Freitag M., Kothe G.O., Margolin B.S., Rountree M.R., Allis C.D., and Tamaru H. 2002. Induction and maintenance of nonsymmetrical DNA methylation in Neurospora. Proc. Natl. Acad. Sci. (suppl. 4) 99: 16485.

Selker E.U., Tountas N.A., Cross S.H., Margolin B.S., Murphy J.G., Bird A.P., and Freitag M. 2003. The methylated component of the Neurospora crassa genome. Nature 422: 893.

Shiu P.K. and Metzenberg R.L. 2002. Meiotic silencing by un- paired DNA: Properties, regulation and suppression. Genetics 161: 1483.

Shiu P.K., Raju N.B., Zickler D., and Metzenberg R.L. 2001. Meiotic silencing by unpaired DNA. Cell 107: 905.

Singer M.J., Marcotte B.A., and Selker E.U. 1995. DNA methylation associated with repeat-induced point mutation in Neurospora crassa. Mol. Cell. Biol. 15: 5586.

Tamaru H. and Selker E.U. 2001. A histone H3 methyltransferase controls DNA methylation in Neurospora crassa. $\mathrm{Na}$ ture 414: 277.

.2003. Synthesis of signals for de novo DNA methylation in Neurospora crassa. Mol. Cell. Biol. 23: 2379.

Tamaru H., Zhang X., McMillen D., Singh P.B., Nakayama J., Grewal S.I., Allis C.D., Cheng X., and Selker E.U. 2003. Trimethylated lysine 9 of histone H3 is a mark for DNA methylation in Neurospora crassa. Nat. Genet. 34: 75.

Wassenegger M., Heimes S., Riedel L., and Sanger H.L. 1994. RNA-directed de novo methylation of genomic sequences in plants. Cell 76: 567. 


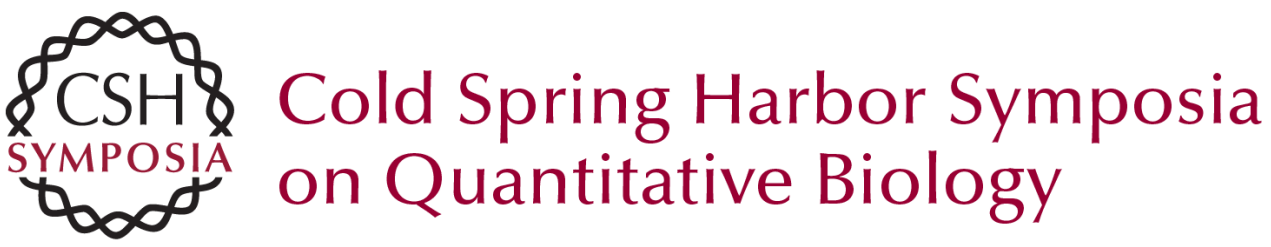

\section{Genome Defense and DNA Methylation in Neurospora}

\section{E.U. SELKER}

Cold Spring Harb Symp Quant Biol 2004 69: 119-124

Access the most recent version at doi:10.1101/sqb.2004.69.119

References This article cites 64 articles, 36 of which can be accessed free at: http://symposium.cshlp.org/content/69/119.full.html\#ref-list-1

\section{License}

Email Alerting Receive free email alerts when new articles cite this article - sign up in Service the box at the top right corner of the article or click here. 